\title{
ELECTRIC FIELD STRENGTH AND TEMPERATURE DEPENDENCE OF CONDUCTION RELAXATION IN AIGaN/AIN/GaN 2D ELECTRON GAS
}

\author{
L. Ardaravičius, O. Kiprijanovič, and J. Liberis \\ Semiconductor Physics Institute, A. Goštauto 11, LT-01108 Vilnius, Lithuania \\ E-mail: linas@pfi.lt
}

Received 10 June 2009; revised 6 November 2009; accepted 18 December 2009

\begin{abstract}
Electrical pulses of ns duration were applied parallel to the interfaces of AlGaN/AlN/GaN samples with a two-dimensional gas channel and an ultra-thin AlN spacer to create electric fields with strength up to $80 \mathrm{kV} / \mathrm{cm}$. Conduction relaxation of the two-dimensional electron gas was measured after the high voltage pulses in temperature range from 86 to $293 \mathrm{~K}$. Results of the conduction relaxation obtained in ns time scale were approximated by an expression containing two exponential components with different time constants. The time constants were chosen to correspond to the relaxation process in the field range from 40 to $60 \mathrm{kV} / \mathrm{cm}$ at various temperatures. Analysis of obtained expressions showed that the smaller constant $\tau_{1}$ slightly depended on temperature and the applied electric field and this was attributed to the electron release after the capture of hot electrons into shallow traps located in the AlN spacer or the AlGaN/AlN interface. The greater constant $\tau_{2}$, which appreciably depends both on electric field and temperature, we attribute to electron thermal release after the capture of hot electrons in the GaN layer. Also, the electrons can be thermally released from the centres in $\mathrm{GaN}$ present due to fluctuations of the bottom of the conduction band. The activation energy associated with the thermal processes is evaluated.
\end{abstract}

Keywords: AlGaN/AlN/GaN, pulsed $I-V$ measurement, high electric field effects, conduction relaxation

PACS: 65.40.-b, 71.55.Eq, 72.20.Ht, 73.50.Fq

\section{Introduction}

High-power field effect transistors, particularly those fabricated using the AlGaN/GaN heterojunction have produced radio frequency (RF) output an order of magnitude greater than GaAs- and InP-based devices. However, the performance changes which represent reliability problems are observed, such as degradation of dc drain current, gain, and RF output power of the devices. Relaxation methods are used for the investigation of such semiconductor properties as conductivity, lifetimes of non-equilibrium carriers, mobility of electrons and holes, and parameters of trapping centres [1]. Such methods can be realized using a relatively simple experimental technique. Conduction relaxation in two-dimensional electron gas (2DEG) channels in $\mathrm{AlGaN} / \mathrm{AlN} / \mathrm{GaN}$ structures was observed in nanosecond time scale after the applied electric fields exceeded $25 \mathrm{kV} / \mathrm{cm}$ [2]. The origin of relaxation was attributed to the release of captured hot electrons. Recent investigations [3] show that the results obtained using the relaxation methods are useful for understanding the barrier properties of the $\mathrm{AlGaN} / \mathrm{AlN} / \mathrm{GaN}$ heterostructure at a high applied electric field. The influence of electric field on barrier properties through changes in spontaneous and piezoelectric polarization and through electrons spreading into the bulk has been revealed. An insertion of a thin undoped layer - AlN spacer - prevents electrons to be injected into $\mathrm{AlGaN}$ from the channel and reduces the remote electron alloy-disorder scattering. Therefore the presence of the spacer increases 2DEG sheet density and mobility [4-6]. However, up to now, the heterostructure thermal data over a broad range of temperatures remains sparse. For example, there is an indication of increase (by a factor of 3 ) of the 2DEG mobility in the AlGaN/GaN samples having a $3 \mathrm{~nm}$ thick i-AlGaN spacer with temperature decrease from 293 to $86 \mathrm{~K}$ [7]. So it is attractive to measure the conduction relaxation in this temperature range aiming to solve the electron drift velocity saturation problem in the 2DEG channels - theory [8] predicts higher saturation values than the experiment: in the latter the saturation appears at $20 \mathrm{kV} / \mathrm{cm}$ for $\mathrm{AlGaN} / \mathrm{AlN} / \mathrm{GaN}$ [3] and the velocity value is about $1 \cdot 10^{7} \mathrm{~cm} / \mathrm{s}$. Recenly, it has been confirmed that nonequilibrium phonons influence 


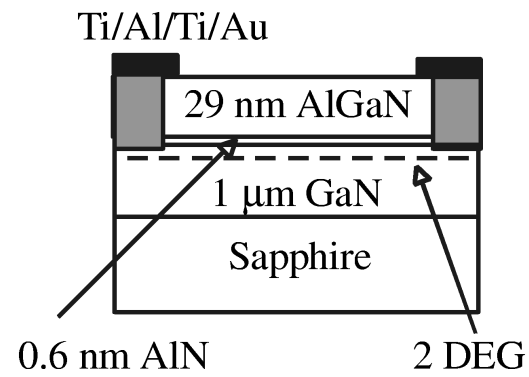

Fig. 1. Schematic diagram of an AlGaN/AlN/GaN heterostructure [3].

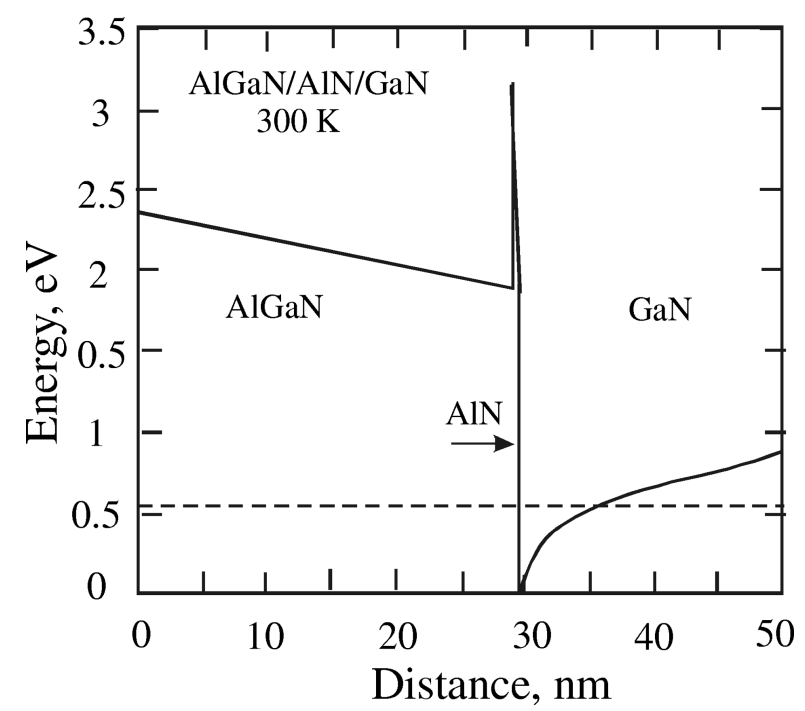

Fig. 2. Schematic conduction band profile (solid line). Dotted line is the Fermi energy [3].

the drift velocity saturation in GaN [9]. Also, it was found that the channel temperature growth only could cause the velocity saturation [10].

This work aims at explaining the hot electron transport in AlGaN/AlN/GaN 2DEG channels at electric fields up to $80 \mathrm{kV} / \mathrm{cm}$, which follows from the results of current-voltage characteristics and conduction relaxation in the channel. The current-voltage characteristics and conduction relaxation measurements were carried out in the temperature range from 86 to $293 \mathrm{~K}$.

\section{Sample characterization}

The samples were grown by the MOCVD method at the University of California (Santa Barbara). The 2DEG channel was located in GaN of AlGaN/AlN/GaN heterostructure with an ultrathin $(0.6 \mathrm{~nm})$ AlN spacer. The 2DEG channel had electron density $n_{0}=9.78$. $10^{12} \mathrm{~cm}^{-2}$ and mobility $\mu=1664 \mathrm{~cm}^{2} /(\mathrm{V} \mathrm{s})$. Sample width $w$ equals to $100 \mu \mathrm{m}$. Coplanar Ti/Al/Ti/Au electrodes were formed at $1080 \mathrm{~K} ; 100 \times 100 \mu \mathrm{m}^{2}$ contact pads (TLM structure) were separated by a gap $d$

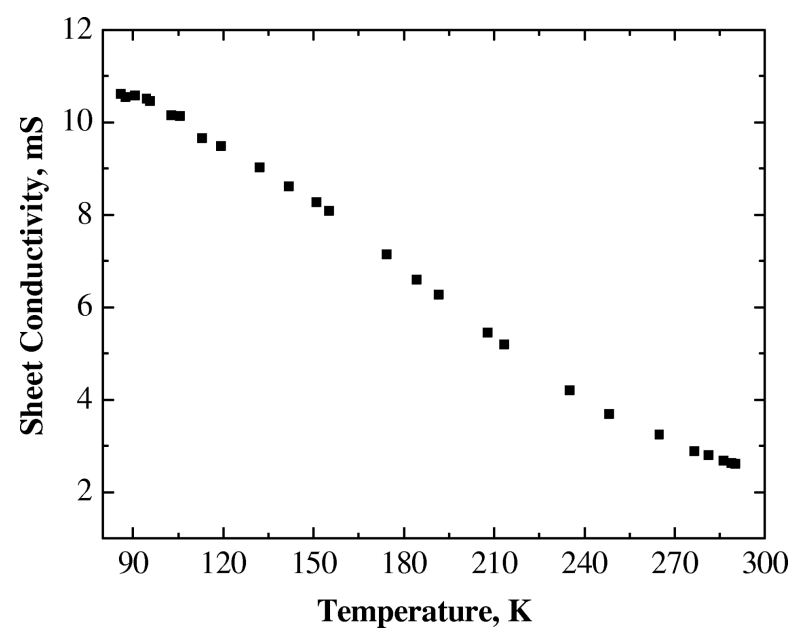

Fig. 3. The $2 \mathrm{DEG}$ channel sheet conductivity versus temperature.

ranging from 5 to $25 \mu \mathrm{m}$. The layer composition and the schematic conduction band potential profile of the AlGaN/AlN/GaN heterostructure channel are presented in Figs. 1 and 2, respectively.

The spacer purpose is to increase the sheet density and mobility in the channel. However, investigations indicate a growing influence of different scattering mechanisms [11] when temperature increases from 80 to $293 \mathrm{~K}$. Figure 3 demonstrates the measured 2DEG sheet conductivity (contact conductivity is not included) vs temperature of the samples. The sheet carrier density can be treated as temperature independent in the range $[12,13]$. Under this assumption one can obtain the increase in the mobility of the samples by a factor of 4 with the decrease of temperature to $80 \mathrm{~K}$.

\section{Experimental set-up}

The block-scheme of an experimental set-up for the current-voltage $(I-V)$ characteristics and the 2DEG channel conduction relaxation measurements after applied high electric fields is shown in Fig. 4. It consists of a high voltage nanosecond pulse generator, a power attenuator (1), a delay line (2), wideband switches (36 ), and a non-matched tee (7) with a test pulse gauge resistor (8) to transmit test generator pulses. It also includes a gauge resistor for high voltage pulse amplitude (9) and thin film attenuators (10). Measurement procedure of the $I-V$ characteristics is described in [2]. Here we focus on conduction relaxation measurements.

The set-up works during the measurements of the conduction relaxation as follows. The electric field $E$ and the current through the sample are obtained from the high field current-voltage measurement ( 4 is switched off during the measurement). The signal of a 


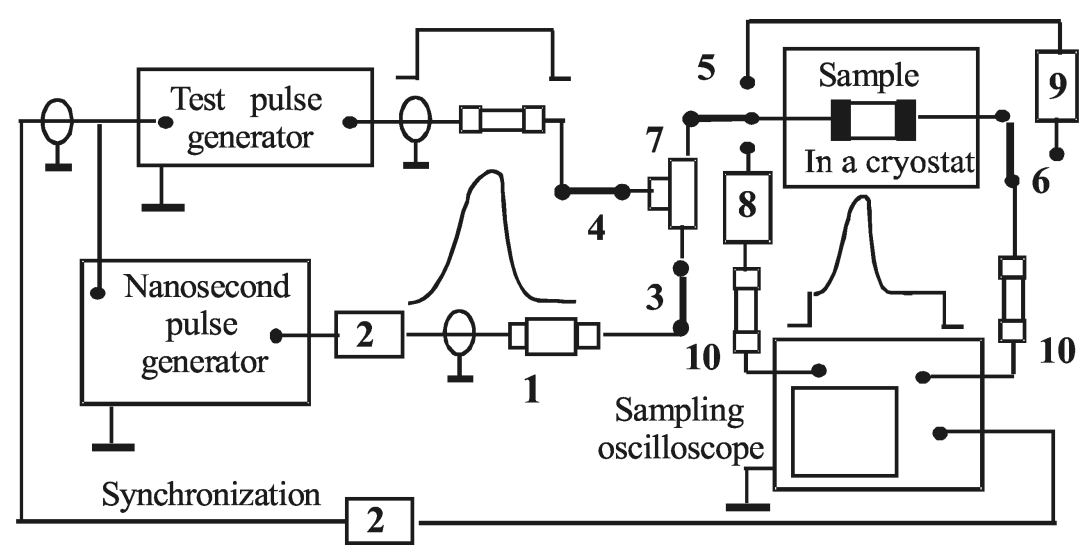

Fig. 4. Block-scheme of the experimental set-up for conduction relaxation measurements. 1 is power attenuator, 2 delay line, $3,4,5,6$ are wideband switches, 7 non-matched tee, 8,9 gauge resistors, 10 thin film attenuators. The waveforms of pulses are included.

high-voltage pulse is transmitted through the sample in cryostat to the oscilloscope input and attenuated so that it does not exceed the maximum acceptable value of the input (typically $1 \mathrm{~V}$ for sampling oscilloscopes). Input attenuation 10 of the second channel is set to be equal to the attenuation of the first one. After that the high voltage pulse is switched off by 3 .

The test generator provides a signal of $0.1-0.15 \mathrm{~V}$ amplitude after the gauge resistor 8 by the switch 5 , when the switch 4 is now on. For conduction relaxation measurement the switches are commutated so that two signals can be transmitted through the sample in cryostat (Fig. 4). Synchronization provides that the test signal reaches the sample before the high voltage one. The oscilloscope sweep is fixed at different coefficients, and the input sensitivity is adjusted to $50-100 \mathrm{mV} / \mathrm{div}$ for the relaxation measurements to be carried out. The back front of high voltage pulse is shifted by the oscilloscope delay to the left part of the screen.

The high current pulse has a tail of ns duration. The pulse form is quasi-rectangular and has a plateau with a maximum, which is set to be a zero time reference for the relaxation time measurements. Two signals are recorded on the screen. The first signal is recorded when the test pulse generator is off by switch 4 and the second one when the generator is on by switch 4 . Information about the 2DEG channel conduction relaxation is obtained from these two signals.

The error of voltage measurements from the oscilloscope is $4 \%$. When the input attenuators with dispersion of parameters in the range $\pm 0.02 \mathrm{~dB}$ are applied the error of measured voltage increases and depends on a number of attenuators. For three attenuators this increase is by $7 \%$ and corresponds to high electric field strengths (above $80 \mathrm{kV} / \mathrm{cm}$ ). The same error is induced for the current measurements. During relaxation measurements the error value of $7 \%$ remains unchanged up
Table 1. Conduction values of a $10 \mu \mathrm{m}$ sample at different temperatures.

\begin{tabular}{ccccccc}
\hline$T, \mathrm{~K}$ & 293 & 272 & 250 & 190 & 146 & 86 \\
$\sigma_{0}, \mathrm{mS}$ & 18.87 & 25 & 31.25 & 52.63 & 71.43 & 91 \\
\hline
\end{tabular}

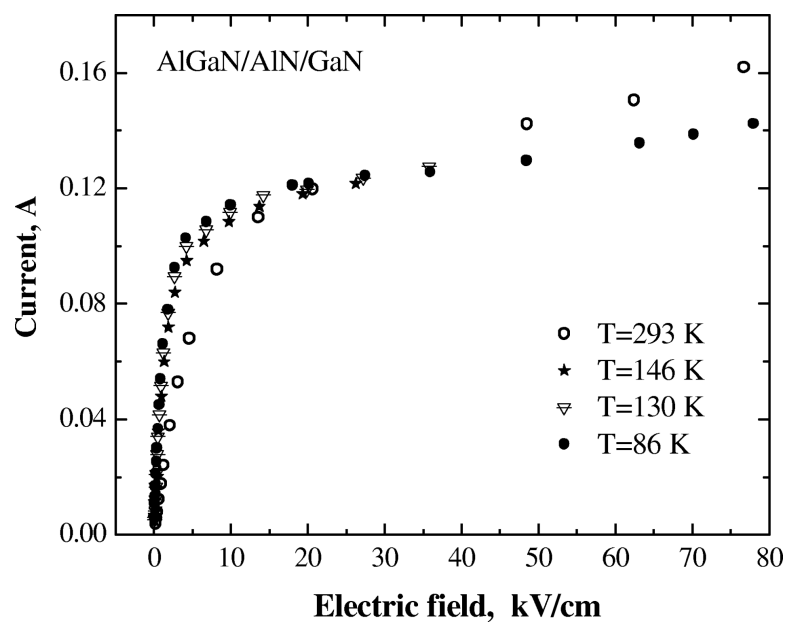

Fig. 5. The $I-E$ characteristics of the sample at different temperatures.

to field strengths of $50 \mathrm{kV} / \mathrm{cm}$. The error increase appears due to higher test pulse amplitude at fields above $50 \mathrm{kV} / \mathrm{cm}$ and achieves $8.5 \%$. Usage of a digital oscilloscope and high voltage limiters could eliminate this additional error growth.

\section{Experimental results}

The conduction relaxation (after applied electric fields parallel to heterointerface) of the sample with a length $d=10 \mu \mathrm{m}$ were investigated. Conduction $\sigma$ is related to the sheet conductivity $\sigma_{\text {sheet }}: \sigma=\sigma_{\text {sheet }} w / d$. Conduction values $\sigma_{0}\left(\sigma(E=0)=\sigma_{0}\right)$ of the sample at different temperatures are placed in Table 1. 


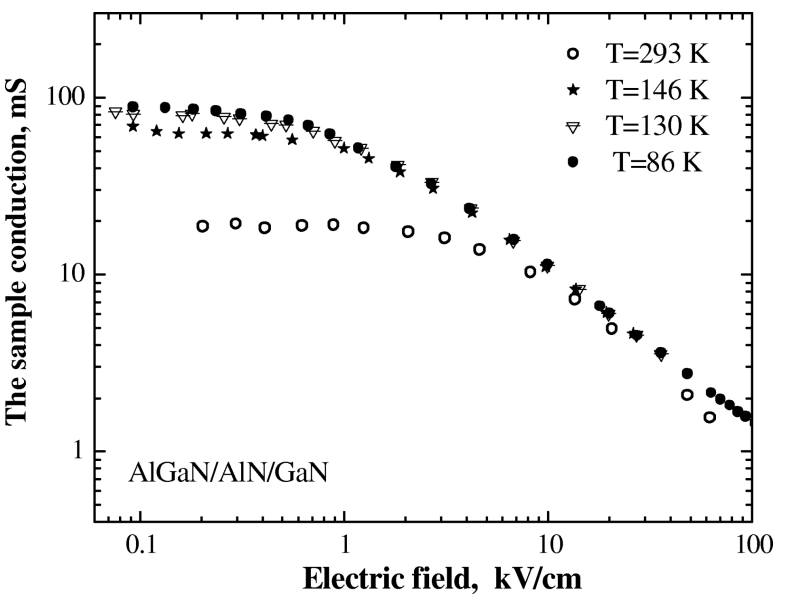

Fig. 6. Conduction of the sample at different applied electric fields and temperatures.

The current-voltage dependences of the sample at different temperatures are presented in Fig. 5. Greater conduction at lower temperatures ensures a sharp increase of $I-E$ curves at small electric fields. But at fields higher than $30 \mathrm{kV} / \mathrm{cm}$ (an average electric field is estimated by $E=\left(V-I R_{\mathrm{c}}\right) / d$, where $R_{\mathrm{c}}$ is the contact resistance) one can see larger current decrease with the decrease of temperature. Ohmic contacts with the resistance $R_{\mathrm{c}}=11 \Omega$ between the metal pads and channel ends were measured. The ohmic regime of the contacts in the investigated field range was probed by measuring the asymmetry of current. No asymmetry was observed. At low electric fields, the influence of the contact resistance to the current is substantial, but at fields exceeding $5 \mathrm{kV} / \mathrm{cm}$ the influence reaches only $1 \%$. The dependences of conduction on the electric field strength of the sample at various temperatures are presented in Fig. 6. At low electric fields, the conduction obeys Ohm's law, but at higher fields, due to hot electron and non-equilibrium phonon effects a nonlinear regime is evident. One can see from Fig. 6 that all advantage in high conduction of the channel at low temperature disappears at electric fields above $10 \mathrm{kV} / \mathrm{cm}$, the change in conduction is small (20\%) between room and liquid nitrogen temperature.

It is worth noting that such $I-V$ curve and conduction versus electric field strength dependences' behaviour on temperature is common for the samples of various lengths.

The conduction relaxation after the high voltage pulses can be approximated with exponentials by the following formula:

$$
\begin{aligned}
\sigma(t)=\left[\sigma_{0}-\sigma(0)\right][ & A_{1}\left(1-\mathrm{e}^{-t / \tau_{1}}\right) \\
+ & \left.A_{2}\left(1-\mathrm{e}^{-t / \tau_{2}}\right)\right]+\sigma(0),
\end{aligned}
$$

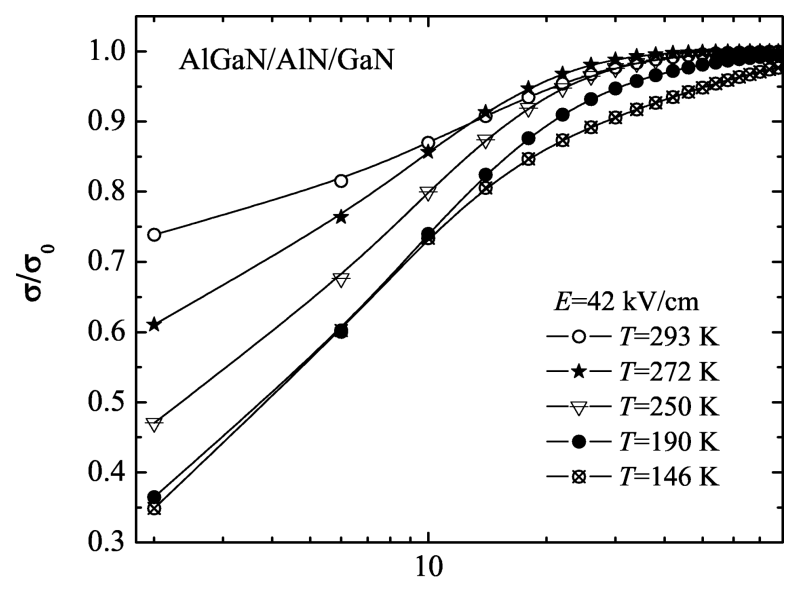

Time, ns

Fig. 7. Calculated low-field normalized conduction relaxation at various temperatures after the high voltage pulse $(E=42 \mathrm{kV} / \mathrm{cm})$. Exponential approximation (1) is performed using average values of $\tau$ from Table 2. Zero time reference is at the maximum of the high voltage pulse.

Table 2. Approximation parameters entering the formula (1) corresponding to $E=42 \mathrm{kV} / \mathrm{cm}$.

\begin{tabular}{cccccc}
\hline$T, \mathrm{~K}$ & $A_{1}$ & $\tau_{1}, \mathrm{~ns}$ & $A_{2}$ & $\tau_{2}, \mathrm{~ns}$ & $\sigma(0), \mathrm{mS}$ \\
\hline 293 & 1 & $11.5 \pm 1$ & 0 & - & 13 \\
272 & 1 & $8 \pm 1.5$ & 0 & - & 12.5 \\
250 & 0.9 & $7.5 \pm 1$ & 0.1 & $18 \mp 3$ & 10 \\
190 & 0.8 & $7 \pm 1$ & 0.2 & $23 \mp 2$ & 10 \\
146 & 0.75 & $5.5 \pm 1$ & 0.25 & $35 \mp 2$ & 10 \\
\hline
\end{tabular}

Table 3. Approximation parameters entering the formula (1) corresponding to $E=49 \mathrm{kV} / \mathrm{cm}$.

\begin{tabular}{cccccc}
\hline$T, \mathrm{~K}$ & $A_{1}$ & $\tau_{1}, \mathrm{~ns}$ & $A_{2}$ & $\tau_{2}, \mathrm{~ns}$ & $\sigma(0), \mathrm{mS}$ \\
\hline 293 & 0.9 & $9 \pm 1$ & 0.1 & $20 \mp 2$ & 9 \\
190 & 0.8 & $8 \pm 1$ & 0.2 & $27 \pm 2$ & 8 \\
146 & 0.6 & $6 \pm 1$ & 0.4 & $55 \pm 5$ & 8 \\
86 & 0.5 & $6 \pm 1$ & 0.5 & $60 \pm 5$ & 8 \\
\hline
\end{tabular}

Table 4. Approximation parameters entering the formula (1) corresponding to $E=59 \mathrm{kV} / \mathrm{cm}$.

\begin{tabular}{cccccc}
\hline$T, \mathrm{~K}$ & $A_{1}$ & $\tau_{1}, \mathrm{~ns}$ & $A_{2}$ & $\tau_{2}, \mathrm{~ns}$ & $\sigma(0), \mathrm{mS}$ \\
\hline 293 & 0.8 & $7 \pm 0.5$ & 0.2 & $20 \mp 2$ & 5 \\
190 & 0.8 & $7 \pm 0.5$ & 0.2 & $30 \pm 2$ & 4 \\
146 & 0.6 & $7 \pm 0.5$ & 0.4 & $50 \pm 4$ & 4 \\
86 & 0.5 & $7 \pm 0.5$ & 0.5 & $60 \pm 4$ & 4 \\
\hline
\end{tabular}

where $\sigma(0)$ is the conduction extrapolated to $t=0$ (zero time reference is at the maximum of the high voltage pulse). $\sigma_{0}$ is the sample conduction at low field using dc measurements.

The obtained experimental results of the normalized conduction relaxation of the sample are on the border or 


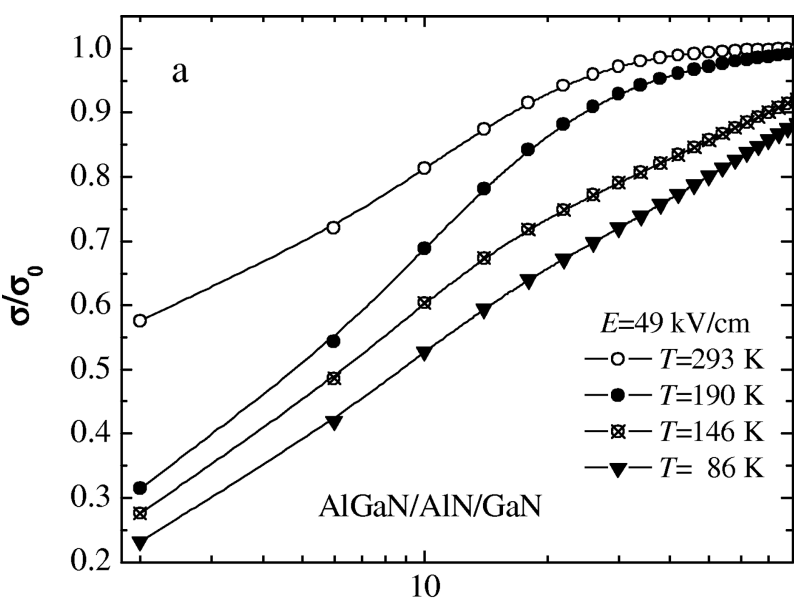

Time, ns

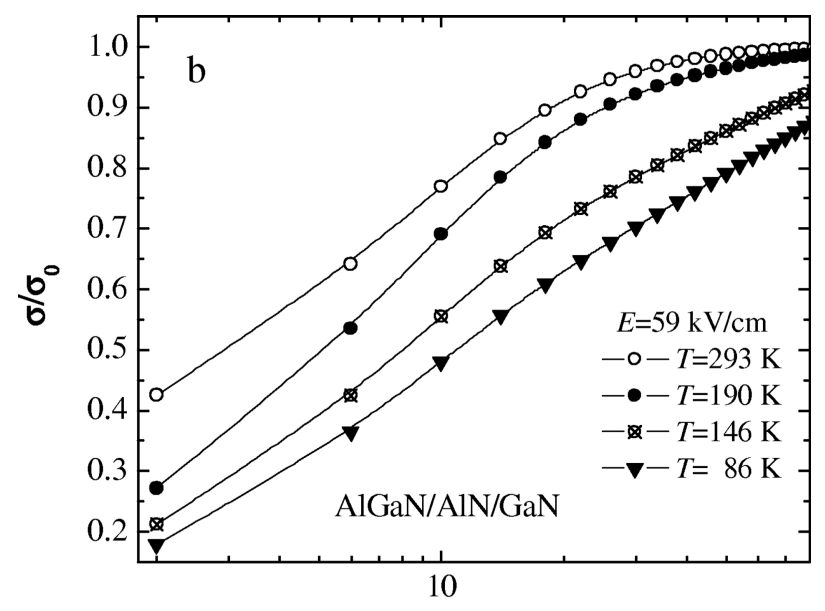

Time, ns

Fig. 8. Calculated low-field normalized conduction relaxation at various temperatures after the high voltage pulses. Exponential approximation (1) is performed using average values of $\tau$ from Tables 3 and 4 . Zero time reference is at the maximum of the high voltage pulse. (a) $E=49 \mathrm{kV} / \mathrm{cm}$, (b) $E=59 \mathrm{kV} / \mathrm{cm}$.

inside the areas bounded by approximation curves with minimal and maximal parameters given in Tables 2-4. Figure 7 demonstrates an approximation of normalized conduction relaxation corresponding to $E=42 \mathrm{kV} / \mathrm{cm}$ at different temperatures with average approximation parameters from Table 2. Approximations of normalized conduction relaxation of the sample corresponding to higher electric fields $(E=49 \mathrm{kV} / \mathrm{cm}$ and $E=$ $59 \mathrm{kV} / \mathrm{cm})$ are presented in Fig. 8(a,b) and the average approximation parameters corresponding to these fields have been chosen from Tables 3 and 4 .

\section{Discussion}

The temperature decrease to $80 \mathrm{~K}$ causes the sample small-field conductivity increase by a factor of 4 as it follows from Fig. 3. However, as seen from Fig. 6, the increase in the sample conduction due to the decrease of temperature is much smaller just when the applied ns electric field reaches $10 \mathrm{kV} / \mathrm{cm}$. At fields from 10 to $25 \mathrm{kV} / \mathrm{cm}$, the emission of longitudinal optical phonons is the main energy dissipation mechanism for hot electrons and possibly is the main factor of their drift velocity decrease [8-10]. Reabsorbing and decay of optical phonons occur in ps time scale and this is invisible in our conduction relaxation ns time scale. It should be noted that the use of ns duration pulses to avoid Joule heating does not prevent the appearance of self-heating effects (heating due to hot phonon decay; local heating, which frequently occurs at defect places) $[11,14]$. We consider a possible presence of this effect in the ns conductivity relaxation, especially at low temperatures, but our estimation indicates that its in- fluence on relaxation processes up to electric fields of $70-80 \mathrm{kV} / \mathrm{cm}$ is insignificant.

Our investigation shows [2] that the threshold of conductivity relaxation process in ns time scale appears at applied electric fields of about $25-30 \mathrm{kV} / \mathrm{cm}$. Firstly, with the decrease of the ambient temperature two processes with the time constants $\tau_{1}$ and $\tau_{2}\left(\tau_{1}<\tau_{2}\right)$ are clearly outlined in the sample conductivity relaxation. By analysing the fitting parameters in Tables 2-4 (electric fields within $42-59 \mathrm{kV} / \mathrm{cm}$ ) we can see that extrapolation of sample conductivity to zero time reference shows a relatively low sample conductivity $\sigma(0)$ (see Fig. 6). Despite a high initial conductivity at low temperatures, one can see that at high electric fields and at the temperature lower than room temperature the presence of nanosecond relaxation processes is evident. This process, characterized by the smaller $\tau_{1}$ which slightly depends both on electric field and temperature, we attribute to the electron release after the capture of hot electrons into shallow traps [15] located in the AlN spacer or an AlGaN/AlN interface. Also, a thin $(0.6 \mathrm{~nm})$ barrier may not prevent the hot electron from tunnelling into AlGaN layer at high electric field.

Secondly, the process of the greater time constant $\tau_{2}$ which appreciably depends both on electric field and temperature, we attribute to hot electron capture in $\mathrm{GaN}$ layer (out of the channel) followed by electron thermal release. By fitting the $1 / \tau_{2}$ dependence on reciprocal temperature $T^{-1}$ with the function $1 / \tau_{2}=$ $B \exp \left[-\Delta \varepsilon /\left(k_{\mathrm{B}} T\right)\right]$, where $B$ is the constant, $k_{\mathrm{B}}$ is the Boltzmann's constant, and $\Delta \varepsilon$ is the thermal activation energy of the trapping centre, we estimate $\Delta \varepsilon=$ $12.5 \mathrm{meV}$. Real space transfer of hot electrons is a pre- 
requisite for the hot electrons to be captured by empty traps because empty traps are localized outside the channel in the bulk. Another scenario is that electrons can be released from the centres present due to fluctuations of the bottom of the conduction band. These fluctuations are caused by the uneven average distribution of $\mathrm{Al}$ content in the $\mathrm{AlGaN}$ barrier and results in saltatory distribution of the 2DEG in GaN along the channel. Also, the activation energy $(12.5 \mathrm{meV})$ estimated by us well coincides with the activation energy $(19 \mathrm{meV})$ of potential fluctuations in AlGaN epilayers [16]. By analysing the Tables $2-4$, one can see that with the decrease of ambient temperature more electrons leave the channel and are captured by empty traps. These are confirmed by the increase of the constant $\tau_{2}$ value and the amplitude $A_{2}$. The rest $3 \mathrm{D}$ electrons move in parallel with the channel electrons. With decrease of the ambient temperature, from 293 to $86 \mathrm{~K}$, due to the capture by empty traps less and less electrons are drifting while the amount of electrons leaving the channel weakly depends on temperature (see Fig. 5, where $I-V$ curve corresponding to $86 \mathrm{~K}$ lies lower than others).

\section{Conclusion}

AlGaN/AlN/GaN samples with a two-dimensional channel were investigated when ns electrical pulses were used. Results obtained from the $I-V$ dependences and conduction relaxation of the 2DEG (measured after the high voltage pulses), measured in temperature range from 86 to $293 \mathrm{~K}$, were used for explanation of hotelectron transport. At electric fields above $25 \mathrm{kV} / \mathrm{cm}$ the results show the presence of two exponential relaxation processes characterized by different time constants. Parameters of the fast and slow relaxation processes differently depend on the applied electric field and temperature. The fast process is attributed to the electron capture by shallow centres in the $\mathrm{AlGaN} / \mathrm{GaN}$ interface or the AlN spacer followed by electron release, while the slow one is attributed to the hot electron capture out of the channel into the bulk $(\mathrm{GaN})$ followed by electron thermal release. Also, the electrons can be thermally released from the centres in $\mathrm{GaN}$ present due to fluctuations of the bottom of the conduction band. The activation energy associated with the thermal processes is evaluated.

\section{References}

[1] M.S. Andreev, L.E. Velikovskii, T.S. Kitichenko, T.G. Kolesnikova, A.P. Korovin, V.G. Mokerov, and
S.N. Yakunin, Deep-level trapping centers in heterostructures for $\mathrm{GaN}$ field-effect transistors, J. Commun. Technol. Electron. 52, 819 (2007).

[2] O. Kiprijanovič, J. Liberis, A. Matulionis, and L. Ardaravičius, Drift velocity measurement and hot electron capture in AlGaN/AlN/GaN, Lithuanian J. Phys. 45, 477 (2005).

[3] L. Ardaravičius, O. Kiprijanovič, and J. Liberis, Relaxation of conductivity in AlGaN/AlN/GaN two dimensional electron gas at high electric fields, Lithuanian J. Phys. 47, 485 (2007).

[4] L. Shen, S. Heikman, B. Moran, R. Coffie, N.Q. Zhang, D. Buttari, I.P. Smorchkova, S. Keller, S.P. DenBaars, and U.K. Mishra, AlGaN/AlN/GaN high-power microwave HEMT, IEEE Electron Device Lett. 22, 457 (2001).

[5] M. Miyoshi, H. Ishikawa, T. Egawa, K. Asai, M. Mouri, T. Shibata, M. Tanaka, and O. Oda, High-electronmobility AlGaN/AlN/GaN heterostructures grown on 100-mm-diam epitaxial AlN/sapphire templates by metalorganic vapor phase epitaxy, Appl. Phys. Lett. 85, 1710 (2004).

[6] R.S. Balmer, K.P. Hilton, K.J. Nash, M.J. Uren, D.J. Wallis, D. Lee, A. Wells, M. Missous, and T. Martin, Analysis of thin AlN carrier exclusion layers in AlGaN/GaN microwave heterojunction field-effect transistors, Semicond. Sci. Technol. 19, L65 (2004).

[7] B. Shen, T. Someaya, and Y. Arakawa, Influence of strain relaxation of the $\mathrm{Al}_{x} \mathrm{Ga}_{1-x} \mathrm{~N}$ barrier on transport properties of the two dimensional electron gas in modulation-doped $\mathrm{Al}_{x} \mathrm{Ga}_{1-x} \mathrm{~N} / \mathrm{GaN}$ heterostructures, Appl. Phys. Lett. 76, 2746 (2000).

[8] M. Ramonas, A. Matulionis, J. Liberis, L. Eastman, X. Chen, and Y.J. Sun, Hot-phonon effect on power dissipation in a biased $\mathrm{Al}_{x} \mathrm{Ga}_{1-x} \mathrm{~N} / \mathrm{AlN} / \mathrm{GaN}$ channel, Phys. Rev. B 71, 075324 (2005).

[9] J. Khurgin, Y. Ding, and D. Jena, Hot-phonon effect on electron velocity saturation in $\mathrm{GaN}$ : A second look, Appl. Phys. Lett. 91, 252104 (2007).

[10] M. Ramonas and A. Matulionis, Monte Carlo simulation of hot-phonon effects in a biased $\mathrm{AlGaN} / \mathrm{GaN}$ channel, Semicond. Sci. Technol. 19, S424 (2004).

[11] Y.-R. Wu and J. Singh, Transient study of self-heating effects in AlGaN/GaN HFETs: Consequence of carrier velocities, temperature, and device performance, J. Appl. Phys. 101, 113712 (2007).

[12] S. Lisesivdin, S. Acar, M. Kasap, S. Ozcelik, S. Gokden, and E. Ozbay, Scattering analysis of 2DEG carrier extracted by QMSA in undoped $\mathrm{Al}_{0.25} \mathrm{Ga}_{0.75} \mathrm{~N} / \mathrm{GaN}$ heterostructures, Semicond. Sci. Technol. 22, 543 (2007).

[13] S. Lisesivdin, A. Yildiz, S. Acar, M. Kasap, S. Ozcelik, and E. Ozbay, Electronic transport characterization of AlGaN/GaN heterostructures using quantitative mobility spectrum analysis, Appl. Phys. Lett. 91, 102113 (2007). 
[14] S. Vitusevich, S. Daniliuk, N. Klein, M. Petrychuk, A. Avksentyev, V. Sokolov, V. Kochelap, A. Beliaev, V. Tilak, J. Smart, A. Vertiatchich, and L. Eastman, Separation of hot-electron and self-heating effects in two-dimensional AlGaN/GaN-based conducting channels, Appl. Phys. Lett. 82, 748 (2003).

[15] A. Matulionis, L. Ardaravičius, J. Liberis, V. Aninkevičius, and D. Gasquet, High-frequency noise in In-
AlAs/InGaAs/InAlAs quantum-well channels, in: Proceedings of the 16th International Conference on Noise in Physical Systems and 1/ f Fluctuations - ICNF2001, p. 517 (2001).

[16] K. Kazlauskas, A. Žukauskas, G. Tamulaitis, J. Mickevičius, M.S. Shur, R.S. Qhalid Fareed, J.P. Zhang, and R. Gaska, Exciton hopping and nonradiative decay in AlGaN epilayers, Appl. Phys. Lett. 87, 172102 (2005).

\title{
AIGaN/AIN/GaN DVIMAČIŲ ELEKTRONŲ DUJŲ LAIDUMO RELAKSACIJOS PRIKLAUSOMYBE் NUO ELEKTRINIO LAUKO STIPRIO BEI TEMPERATŪROS
}

\author{
L. Ardaravičius, O. Kiprijanovič, J. Liberis \\ Puslaidininkiu fizikos institutas, Vilnius, Lietuva
}

\begin{abstract}
Santrauka
AlGaN/AlN/GaN bandiniai su dvimatemis elektronų dujomis ir labai plonu AlN tarpiniu sluoksniu buvo veikiami nanosekundinès trukmés iki $80 \mathrm{kV} / \mathrm{cm}$ stiprio elektriniais laukais, nukreiptais lygiagrečiai darinio plokštumai. Dvimačių elektronų dujų laidumo relaksacija buvo išmatuota, išjungus stipraus elektrinio lauko impulsą, temperatūrų intervale nuo 86 iki 293 K. Nanosekundinèje skalèje gauti laidumo relaksacijos duomenys buvo aproksimuoti išraiška, turinčia du eksponentinius narius su atitinkamomis laiko
\end{abstract}

konstantomis. Šių išraiškų analizė rodo, kad trumpesnioji laiko konstanta nežymiai priklauso nuo aplinkos temperatūros ir elektrinio lauko stiprio, ir ji siejama su elektronu išlaisvinimu iš seklių pagavimo lygmenų AlN tarpiniame sluoksnyje arba AlGaN/AlN sandūroje. Ilgesnioji laiko konstanta yra siejama su elektronų šiluminiu išlaisvinimu iš pagavimo lygmenų GaN sluoksnyje. Taip pat elektronai gali būti termiškai išlaisvinami iš pagavimo centrų $\mathrm{GaN}$, susidariusių dẻl laidumo juostos dugno fliuktuacijų. Ivertinta šiluminio proceso aktyvacijos energija. 